\title{
Nitrate Pollution Distribution and Source Identification in an Alluvial Aquifer
}

\author{
Lin $\operatorname{LIN}^{1, a,{ }^{*}}$, Qing-Wei BU ${ }^{1, b}$, Yan-Yan $\mathrm{LI}^{1, \mathrm{c}}$, Jian LIU ${ }^{1, \mathrm{~d}}$, Yi TANG ${ }^{1, \mathrm{e}}$ and Mei-Hua \\ SONG $^{1, f}$
}

\author{
${ }^{1}$ Shandong Provincial Key Laboratory of Water Resources and Water Environment, Water \\ Research Institute of Shandong Province, Jinan, Shandong, 250014, China \\ allin_mail@126.com, bbqw1980@163.com, '824022542@qq.com, cwater_liujian@163.com, \\ etangyi1023@hotmail.com, 'smh900720@163.com
}

Keywords: Groundwater, Nitrate, Stable nitrogen isotope.

\begin{abstract}
Characteristics and spatial distribution of nitrate concentration and its isotopic composition were used for identifying pollution mechanisms and sources in groundwater. An aquifer downstream of Dagu River in Jiaozhou city was taken as an example which was seriously contaminated with nitrates. The results showed that the study area could be divided into 4 divisions. Division A planted many kinds of vegetables with high nitrate contents and low $\delta^{15} \mathrm{~N}$ ratios. High values of concentrations and $\delta^{15} \mathrm{~N}$ ratios were appeared in Division B which mainly grew Chinese cabbage. Low nitrate concentrations were observed in Division C, whereas the wide range of $\delta^{15} \mathrm{~N}$ values may reflect the contribution of both natural and anthropogenic sources. Groundwater nitrate at Division D were mainly affected by surface water.
\end{abstract}

\section{Introduction}

Nitrates contamination has been one of the main contaminants of groundwater for drinking water in the world, which has been widely concerned due to its close correlation with human health [1, 2]. There are many causes of increasing $\mathrm{NO}_{3}{ }^{-}$content in ground water, such as seasonal and interannual changes of precipitation, fertilizer application, sewage discharge, and excrement of livestock and poultry. Pollution sources can be divided into two categories: point source and non-point source. Point source pollution is discharged into water body through sewage pipe network, including urban sewage, industrial sewage, domestic sewage and waste water from some metal mines. Agricultural pollution occupies the largest share to non-point pollution, including excessive fertilizer application in farmland, soil and water loss caused by farmland or forestland, nitrogen loss in livestock and poultry breeding, sewage irrigation and so on[3]. Thus a better understanding of the contribution from different pollution sources to groundwater nitrate is of great significance for groundwater pollution control.

Nitrogen isotope method is an effective tool to identify the pollution sources of groundwater nitrate [4-6]. The nitrogen in groundwater is the result of various biological, chemical and physical processes. Because the nitrogen isotopic composition of some pollution sources is even overlapping, this should be conducted in conjunction with other relevant data such as hydrogeological condition, land use condition and water quality data [7]

The study area is located in the southwest of groundwater source in Dagu River, which belongs to Jiaozhou city in administrative division and has been an important water supply source of Qingdao city. However, water supply wells were stopped a decade ago due to serious nitrate pollution. The study aims at identifying the sources of nitrate pollution by stable nitrogen isotope, which can provide scientific evidence for rural groundwater protection.

\section{Materials and Methods}

14 water samples were collected from the study area in November 2008. Among them 11 were sampled in irrigation wells and drinking wells, other 3 were sampled from Dagu river, Jiaolai river and Limin river respectively. The amount of nitrogen of water samples was determined according to 
the standards of groundwater, surface water and drinking water quality. The concentrations of nitrate, Nitrites and ammonia were measured by spectrophotometry, total nitrogen (TN) was measured by digestion method. Stable nitrogen isotopic composition of samples was analyzed using Kjeldahl digestion with sulfuric acid and mixed catalyst [6]. Cooled digestates were treated with $\mathrm{NaOH}$, then steam-distilled and trapped in dilute $\mathrm{H}_{2} \mathrm{SO}_{4}$ solution. Distillates were evaporated dryness on a water bath. Under vacuum conditions, the $\mathrm{N}_{2}$ was released by reacting samples with $\mathrm{NaBrO}$ and the $\delta^{15} \mathrm{~N}$ value of nitrate was determined by MAT-251 mass spectrometer. Analytical precision is within $0.05 \%$.

\section{Results and Discuss}

\section{Statistical Characteristics of Nitrogen Contents and Isotopic Composition}

Statistical characteristics of nitrogen content and isotopic composition were listed in Table 1 . The inorganic nitrogen in the water body of the research area is dominated by nitrate accounting for $88.75 \%$ of $\mathrm{TN}$. $\mathrm{NO}_{3}{ }^{-}-\mathrm{N}$ concentration ranged between $6.23-173.57 \mathrm{mg} / \mathrm{L}$, the mean value was 46.03 $\mathrm{mg} / \mathrm{L}$, and the max/min ratio reached 27.86. Among them more than $60 \%$ exceeded the limit of drinking water standard $(20 \mathrm{mg} / \mathrm{L})$, and the maximum achieved about 8 times higher than the standard limit. These analyses indicted that water body in the study area was subject to obvious nitrate pollution. In terms of sample type, $\mathrm{NO}_{3}{ }^{-} \mathrm{N}$ in groundwater samples showed a peak of $173.57 \mathrm{mg} / \mathrm{L}$ and a mean value of $53.6 \mathrm{mg} / \mathrm{L}$, which were 6 and 4 times that of surface water, respectively.

Table 1 statistical characteristics of nitrogen content and nitrate nitrogen isotopes in water samples

\begin{tabular}{|c|c|c|c|c|c|c|c|}
\hline Sample type & Parameters & $\begin{array}{c}\mathrm{NO}_{3}{ }^{-}-\mathrm{N} \\
(\mathrm{mg} / \mathrm{L})\end{array}$ & $\begin{array}{c}\mathrm{NO}_{2}{ }^{-}-\mathrm{N} \\
(\mathrm{mg} / \mathrm{L})\end{array}$ & $\begin{array}{l}\mathrm{NH}_{3}-\mathrm{N} \\
(\mathrm{mg} / \mathrm{L})\end{array}$ & $\begin{array}{c}\mathrm{TN}(\text { in } \mathrm{N}, \\
\mathrm{mg} / \mathrm{L})\end{array}$ & $\begin{array}{l}\text { Proportion of } \\
\text { nitrate in TN } \\
(\%)\end{array}$ & $\begin{array}{c}\delta^{15} \mathrm{~N}_{-\mathrm{NO}_{3}}^{-} \\
\text {(\%o) }\end{array}$ \\
\hline \multirow{3}{*}{ Groundwater } & Minimum & 14.12 & - & - & 15.45 & $63.05 \%$ & 0.76 \\
\hline & Maximum & 173.57 & 0.337 & 0.07 & 185.81 & $98.31 \%$ & 47.15 \\
\hline & Average & 53.6 & & & 64.73 & $88.11 \%$ & 11.16 \\
\hline \multirow{3}{*}{ Surface water } & Minimum & 6.23 & - & - & 6.41 & $86.68 \%$ & 9.94 \\
\hline & Maximum & 27.27 & 0.078 & - & 31.46 & $97.25 \%$ & 14.36 \\
\hline & Average & 18.29 & & & 20.60 & $91.09 \%$ & 12.42 \\
\hline \multirow{3}{*}{$\begin{array}{c}\text { Total } \\
\text { samples }\end{array}$} & Minimum & 6.23 & - & - & 6.41 & $63.05 \%$ & 0.76 \\
\hline & Maximum & 173.57 & 0.337 & 0.07 & 185.81 & $98.31 \%$ & 47.15 \\
\hline & Average & 46.03 & & & 55.27 & $88.75 \%$ & 11.43 \\
\hline
\end{tabular}

(“-” means below detectable limit)

The $\delta^{15} \mathrm{~N}$ of $\mathrm{NO}_{3}{ }^{-}$showed a range of $0.76 \%$ - $47.15 \%$ with a max/min ratio of 62.04 (Table 1 ), reflecting multiple sources of nitrogen information. Among them the $\delta^{15} \mathrm{~N}$ values from surface water samples displayed a narrow range between $9.94 \%$ - $14.36 \%$ and a small max/min ratio of 1.44 . That revealed groundwater nitrate in the study area was not derived from a single source, but a mixture of various sources. Fig. 1 depicted the correlation between the concentration and isotopic composition of nitrate. The very small coefficient value (0.15) means that the level of nitrate concentration does not correspond to its isotopic composition. 


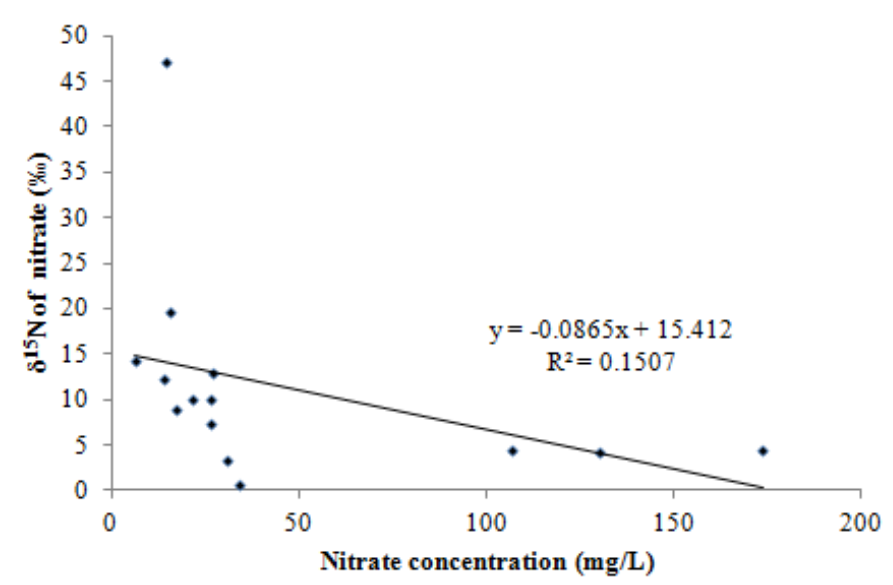

Fig. 1 The correlation between the concentration and isotopic composition of nitrate

\section{Spatial Distribution Characteristics of Nitrate Content and Isotopic Composition.}

Fig. 2 described spatial distribution characteristics of nitrate concentration and its isotopic composition in order to better understand the mechanism of nitrate pollution in the study aquifer. It was clear that nitrate values showed an alarming decreasing trend from northeast to southwest, which is consistent with the direction of groundwater flow. The peak appeared in the north boundary of the study area. The possible explanations were due to certain differences in agricultural planting structure and rural settlements. The northern part of the research area mainly grows vegetables, which are important suppliers of Qingdao city. The rural residential area occupies a large share of land cover in the south, the cultivated land mainly grows food crops and its area is much less than the north.
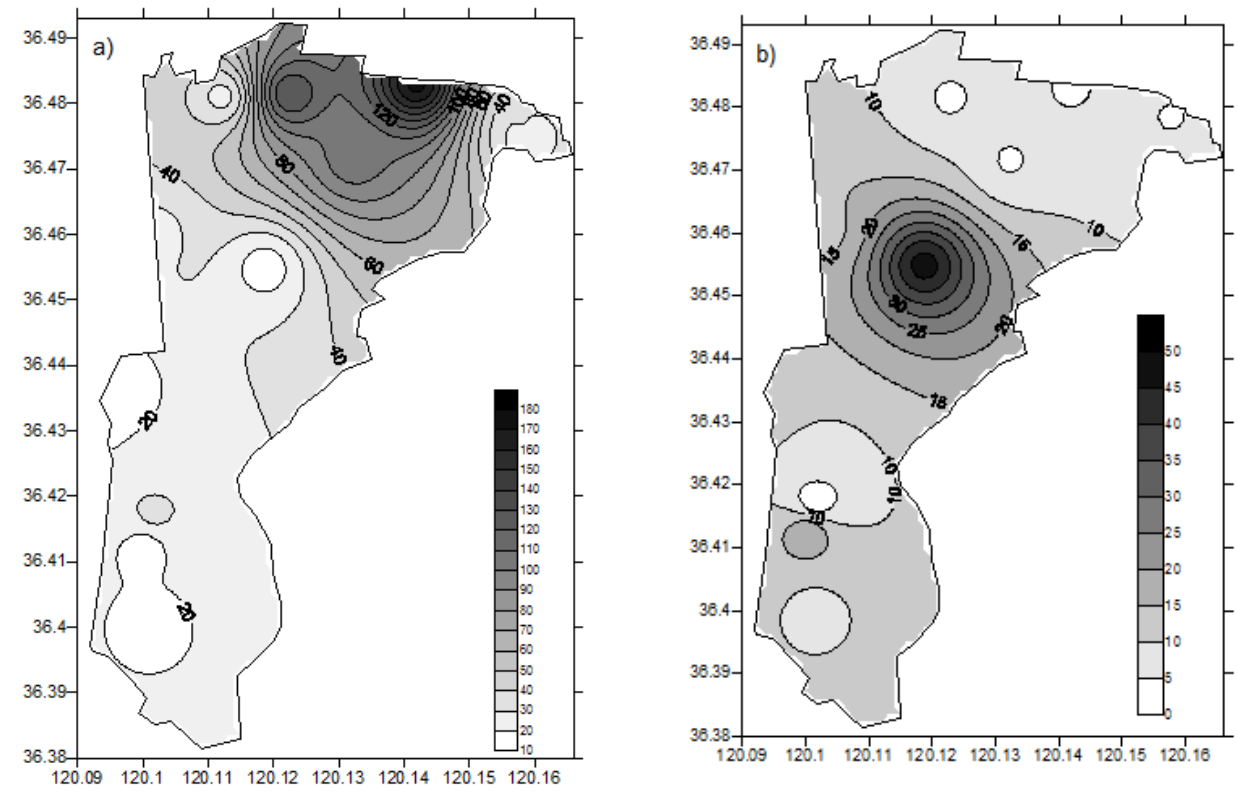

Fig. 2 The contour map of nitrate content (a) and isotopic composition (b)

High $\delta^{15} \mathrm{~N}$ values of $\mathrm{NO}_{3}{ }^{-}$appeared in the middle of the study area (see Fig.2b). In combination with the groundwater hydraulic condition, planting structure and possible pollution sources, the environmental signatures reflected by the stable nitrogen isotopic composition of nitrate were comprehensively analyzed. Based on these analyses, the study area could be identified for 4 units (see Fig.3). The $\delta^{15} \mathrm{~N}$ values of river nitrate ranged between $9.94 \%$-14.36\%o with an average of $12.42 \%$. The agricultural land along the river and the residential land in the south displayed a similar range between $9.00 \%$ o- $12.21 \%$ with an average of $10.4 \%$. It means that the surface water 
has a hydraulic connection to groundwater, groundwater nitrate are mainly affected by surface water at the division named Division D. As mentioned above, the northern part of the research area was mainly planted with agricultural vegetables such as Chinese cabbage, scallion, ginger and potato. According to the variation range of $\delta^{15} \mathrm{~N}$ of nitrate, the area could be classified as two divisions (Division A and Division B). Division A had the $\delta^{15} \mathrm{~N}$ values in the range between $3.35 \%-4.52 \%$, which is close to the range of nitrate nitrogen fertilizer. Division B mainly produced Chinese cabbage, its $\delta^{15} \mathrm{~N}$ value achieved $47.15 \%$, which reached the values from human and animal feces. It could be observed that manure was applied to the fields at the division. This may be the results of different types of planted vegetables. At Division $C$ the nitrate concentrations met the drinking groundwater standard of $20 \mathrm{mg} / \mathrm{L}$, which may represent the background value in the study area. Likewise, its $\delta^{15} \mathrm{~N}$ values ranged between $0.76 \%$-19.70\%. The sampling site with a $\delta^{15} \mathrm{~N}$ value of $0.76 \%$ was located in rural residential area, corresponding to the isotopic characteristics of atmospheric N2, which might indicated that groundwater nitrate was derived from the atmosphere, rather than anthropogenic sources. Samples with a $\delta^{15} \mathrm{~N}$ value greater than $10 \%$ are collected from agricultural well, reflecting the contribution of human sources such as domestic sewage and irrigation wastewater.

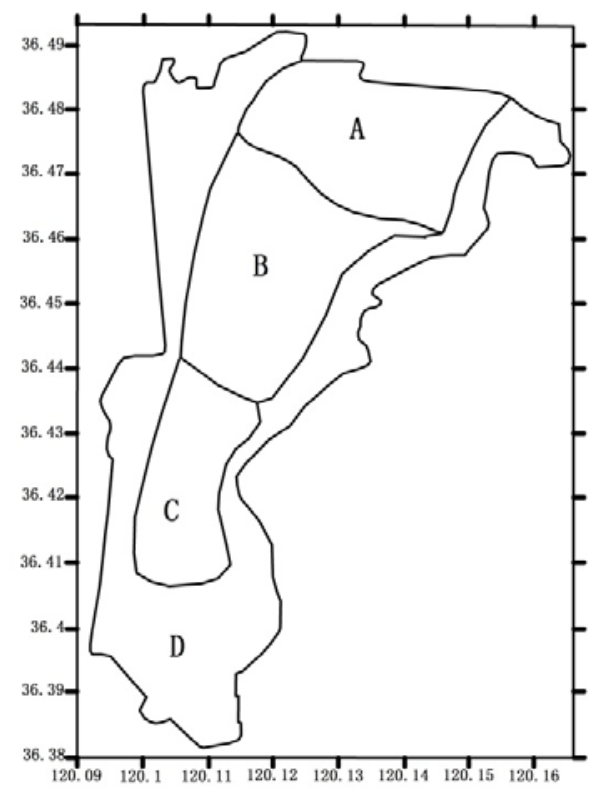

Fig. 3 Divisions of nitrate sources identified by nitrate isotopic composition.

\section{Conclusions}

Nitrogen in the water of study area is existed mainly in the form of nitrate. Nitrate concentration decreases significantly along groundwater flow direction. Groundwater in the northern area is highly contaminated. A large range of stable nitrogen isotopic composition in groundwater nitrate revealed the contribution of multiple sources. Compared to groundwater, nitrate of river water were slightly polluted, and a small range of $\delta^{15} \mathrm{~N}$ values revealed they might have the same source. In combination with the groundwater hydraulic condition, planting structure and possible pollution sources, the stable nitrogen isotopic composition of nitrate were successfully applied for source identification.

\section{Acknowledgement}

This research was financially supported by the Shandong Provincial Natural Science Foundation, China (ZR2015EM007) and Shandong provincial water resources research project (SDSLKY201608). 


\section{References}

[1] M. Dan-Hassan, P. Olasehinde, A. Amadi, et al. Spatial and temporal distribution of nitrate pollution in groundwater of Abuja, Nigeria. Int. J. Chem. (2012) 94-104.

[2] G. Gulis, M. Czompolyova, J. R. Cerhan. An ecologic study of nitrate in municipal drinking water and cancer incidence in Trnava Distric, Slovakia. Environmental Research Section A. 88(2002) 182-187.

[3] A. Zaporozec. Groundwater contamination inventory: a methodological guide. IHPVI Series on Groundwater No 2. UNESCO. 2002

[4] T. H. E. Heaton, M. E. Stuart, M. Sapiano M, et al. An isotope study of the sources of nitrate in Malta's groundwater. Journal of Hydrology.. 414-415 (2012) 244-254.

[5] Y. Zhang, F. D. Li, Q. Y. Zhang, et al. Tracing nitrate pollution sources and transformation in surface- and ground-waters using environmental isotopes. Science of the Total Environment. 490 (2014). 213-222.

[6] G. X. Xing , Y. C. Cao, S. L. Shi, et al. N pollution sources and denitrification in waterbodies in the Taihu Lake region. Science in China, Series B. 44 (2001) 304-314.

[7] D. Kaown, D. C. Kohl, B Mayer, et al. Identification of nitrate and sulfate sources in groundwater using dual stable isotope approaches for an agricultural area with different land use (Chuncheon, mid-eastern Korea). Agriculture, Ecosystems and Environment. 132 (2009) 223-230. 